\title{
Revisiting the life of things: A cognitive semiotic study of the agency of artefacts in Amazonia
}

\author{
Juan Carlos Mendoza-Collazos \& Göran Sonesson
}

\begin{abstract}
Many contemporary scholars have recently defended the idea that the agency of things is symmetrical and equivalent to human agency. We propose an alternative approach to artefacts' agency based on a field study concerned with contextually situated observations of the process of design of artefacts in Amazonia. By means of participant observation and interviews, we address the role of artefacts in relation to human agency. In so doing, we focus on the human-unique capacity for design as it is related to cognitive resources such as intentionality, decision-making, planning, and volitional adaptations of the material world to human purposes. We argue that such cognitive resources are ultimate manifestations of human agency. The findings allow us to conclude that artefacts possess a special form of agency, which operates in different ways from the agency of true agents. This agency is derived: it depends on the actions of true agents, with either function as remote intentions or are required for the artefact to work at the moment of use. Thus, the relation between artefacts and agents is asymmetrical. Given that the derived agency of artefacts allows people to expand their own agency, we propose the notion of enhanced agency for the prosthetic incorporation of artefacts into the agentive capabilities of human agents.
\end{abstract}

Keywords: enhanced agency, artefacts, material agency, cognitive semiotics, design, intentionality

\section{Introduction}

In recent decades, there has been a lively debate within several disciplines such as cognitive science, philosophy, and archaeology concerning the role of artefacts in relation to human agency. Some scholars have claimed that interactions between artefacts and persons are symmetrical. Malafouris (2013, p. 244), for instance, states that artefacts "should be seen as continuous, integral, and active parts of the human cognitive architecture". While this statement may be open to several interpretations, the central import of the claim is that material things are, in a sense, equal partners to human beings with respect to agency.

In contrast, other scholars have claimed that artefacts lack meaning on their own, and that their functions depend on animate agents, human or not, endowing them with meaning. Such approaches are based on phenomenology (Merleau-Ponty 1995: 213-215; Sonesson, 2015; to appear; Pielli \& Zlatev, 2020), agentive semiotics (Niño, 2015; Mendoza-Collazos, 2016), or cognitive science (Adams \& Aizawa, 2001; Rupert, 2004). From such a perspective, artefacts only have derived agency (Niño, 2015) or remote intentionality (Sonesson, 1999, 2015) and there is an inherent asymmetry in the relation between true agents and artefacts.

This article offers some arguments relevant to this debate, based on fieldwork in Colombian Amazonia, aiming to pinpoint the role of artefacts within the framework of human agency. The study focuses on the process of design as a clear manifestation of human agency, inquiring into the nature of this process, and what it implies for our understanding of the agency of things. In so doing, it brings Malafouris' notion of methodological fetishism (Malafouris 2013, p. 133) back to the ground on which it was first elaborated. In Section 2 we briefly outline the conflicting approaches to agency mentioned above. Section 3 introduces the animistic explanation of the relationship between humans and artefacts in Amazonia featured in anthropology. The empirical study itself is presented in Section 4. The methods for data collection were based on participant observation and interviews, framed within the conceptualempirical loop of cognitive semiotics, which supposes a continuous dialectic between conceptual analysis (guided by phenomenology), and empirical studies (Zlatev, 2015). Finally, after the general discussion offered in Section 5, we draw some conclusions in Sections 6. 


\section{Conflicting theoretical approaches to the agency of things}

In this section, we briefly review two accounts of the notion of agency in artefacts, corresponding to the two conflicting approaches outlined in the introduction. The first is that of Malafouris (2013, inter alia), which claims that the agency of things - although different in nature - is symmetrical and equivalent to human agency. The other is a cognitive semiotic approach to agency, informed by agentive semiotics and phenomenology, according to which meaning is only bestowed on artefacts by animate agents.

\subsection{Material agency}

Malafouris' theory of material agency aims to eliminate anthropocentrism in the relationship between human beings and artefacts; it is meant to serve as "a wake-up call, for social scientists and archaeologists, to encourage them to consider agency non-anthropocentrically, as a situated process in which material culture is entangled" (Knappett \& Malafouris, 2008, p. xii). Malafouris (2013) recognizes that artefacts do not have human-like agency, as they do not interact like human beings. Although he admits that things have their own way of operating according to their materiality, he maintains that the process of fetishization induces us to treat them as agents (Malafouris, 2013, p. 134). ${ }^{1}$

Malafouris claims that material agency plays an active part in the creative process of manufacturing, in opposition to approaches in which the ultimate source of creativity resides in the mind of the creator. According to Malafouris, prior intentions of human actions have no pragmatic effects in the world (Malafouris, 2008, p.30), and thus human creative agency consists (at most) in intentions in action, which are modulated by material agency. ${ }^{2}$ This conception of the role of artefacts is based on a radical interpretation of theoretical frameworks such as the extended mind hypothesis (Clark \& Chalmers, 2010), action-network theory (Latour, 1993, 2005), embedded and dynamic cognition (Ward, 2002; Cowley \& ValléeTourangeau, 2013), and radical enactivism (Hutto \& Myin 2013; 2017). According to Malafouris, (2013, p. 244), artefacts "should be seen as continuous, integral, and active parts of the human cognitive architecture". Not only does this assume that interactions with artefacts influence cognition, but also that material things are part and parcel of human cognition. In short, Malafouris suggests that agency is not the property of human beings or things but the emerging property of material engagement (ibid., 2013, p. 18) and that agency can only be understood as a materially engaged cognitive process. ${ }^{3}$

\footnotetext{
${ }^{1}$ The process of fetishization is elaborated by Malafouris (2013, Chapter 6). To clarify the difference between animism, fetishism, and totemism is beyond the scope of the present article (see Viveiros De Castro 2004, pp. 45 ff.; Descola 2005, pp. 229 ff.). Suffice it to say that, in the following, we are interested in the common core of these notions, which involves the postulation of a symmetric relation between animate beings and artefacts.

2 The notion "intention in action" was introduced by Searle $(1979,1983)$ in opposition to "prior intentions", within the framework of his theory of action. For example, Searle $(1979$, p. 258) argued that "intention in action just is the intentional content of the action; the action and the intention are inseparable", and that "many of the actions one performs, one performs quite spontaneously, without forming, consciously or unconsciously, any prior intention to do those things." Importantly, Searle notes that intentions in action, as well as prior intentions, are intentional (Searle 1979, p. 259), that is, these actions still imply agency in the case of the performer of the action.

${ }^{3}$ For a detailed critical review of this approach, see Mendoza-Collazos (2020).
} 


\subsection{A cognitive semiotic approach to agency}

In contrast, agentive semiotics (Niño, 2015; Mendoza-Collazos 2016) offers an approach to the notion of agency within a phenomenological framework. As explained by Mendoza-Collazos (2016), this approach falls naturally within the new discipline of cognitive semiotics, which is concerned with the "transdisciplinary field focused on the multifaceted phenomenon of meaning" (Zlatev 2015, p. 1043). Much research within cognitive semiotics employs phenomenological analysis in combination with other methods, such as interviews and experiments, understood as different modes of access to knowledge (Zlatev 2009, p. 179). The purpose of this new discipline is to build a bridge between the natural sciences and the human sciences, in the pursuit of an integrated account of different kinds of meaning making (Sonesson 2009; Zlatev 2018).

In such an approach an agent is basically an entity with a capability to act, without prejudging on the level of awareness required. The environment, both natural and artificial, as well as other agents play a fundamental role in an agent's meaning making. Meaning emerges when such a situated agent acts in the world. Agency is thus the capability to act on the basis of the agent's intrinsic intentionally, which implies that agents must be living beings. ${ }^{4}$ From such a perspective, artefacts do not fulfil the necessary conditions for being true agents. Rather, their agency is derived: a special kind of agency assigned by true agents and their actions, which is a prerequisite for artefacts to obtain meaning (Niño, 2015; Mendoza-Collazos, 2015, 2016; cf. Sonesson, 1999). Derived agency is thus parasitic on the agency of living beings. This can be illustrated by the example of a photograph automatically produced by the very acts of the horses crossing the finishing line of the race. As Sonesson (1999) explains, this could never have happened if not for the people rigging up a camera at a particular place, directing its objective in a particular direction, and installing a mechanism which triggers the camera off, not to mention the invention of the camera, nor that of horse racing. Thus, the camera possesses only remote intentionality, which is one form of derived agency, rather than intrinsic intentionality, which is the hallmark of true agents.

In this context, intentionality should not simply be understood as a synonym for purposefulness, but in the much broader Husserlean sense of being an object of consciousness, irrespectively of the level of explicitness of such consciousness. It can be related to another notion introduced by Husserl (1939, pp. 334 ff.; 1954, pp. 361, 372 ff.; 1974, pp. 314 ff.): sedimentation, which is the process by means of which previous acts of experience are constantly being accumulated, thereafter forming the background which contributes to shape and condition more recent experiences. One may further distinguish genetic and generative sedimentation (Husserl 1973; Steinbock 1995; Welton 2000). Every object in our experience has a genetic dimension: it results from the layering, or sedimentation, of the different acts in our personal experience. Thus, genetic phenomenology studies the genesis of the meanings of things within one's own stream of consciousness, with the term "genetic" evoking the idea of the life of an individual from the cradle to the grave. On the other hand, generative phenomenology studies how meaning, as found in our experience, is generated in historical processes of collective experience over time. The term "generative" is also meant to evoke the idea of the chain of generations following each other. ${ }^{5}$

If we apply these distinctions to the case of the camera at the finishing line referred to above, it is clear that the creation of the necessary equipment epitomizes generative sedimentation, which goes way beyond our present experience. In contrast, the setting up of the camera at the finishing line at the horse race is at least potentially a case of genetic

\footnotetext{
${ }^{4}$ Mendoza-Collazos (2015; 2016), Niño (2015) and Zlatev (2009; 2018) provide extensive argumentation and elaboration of these claims.

${ }^{5}$ Further elaborations of the notion of sedimentation are provided by Sonesson (to appear a, b) and Blomberg (2019), the latter with a focus on language.
} 
sedimentation. As we show in Section 4, these distinctions are clearly relevant to the praxis of wise men in the Amazonas.

To summarize, derived agency, remote intentionality and sedimentation are theoretical concepts that could be used to explain the agency of things within a cognitive semiotic perspective, which present the relationship between artefacts and human beings as being asymmetrical, in contrast to the perspective of material agency, discussed in the previous subsection. In the following sections, we consider evidence that could help us arbiter between the two opposing views.

\section{Animism in Amazonian worldviews}

Santos-Granero (2009) summarizes a series of articles on "the life of things" within Amazonian cultures, claiming that this is not to be understood as a metaphor, but a true reflection of native Amazonian perceptions. In this context, the notion of agency is understood in its "classical sense of a subject's conscious capacity to act upon or exert power over other beings and the surrounding world" (Santos-Granero, 2009, p. 24). According to the evidence presented in the reviewed studies, the agency of things in Amazonia is understood in diverse ways. Some native cultures regard artefacts as being without any capability to act, while others regard at least some artefacts as possessing superhuman agency; and there are multiple degrees of agency attribution in between. According to Viveiros de Castro (2004, pp. $37 \mathrm{ff}$.), the native Amazonian cosmology has a conception of the origin of life exactly opposite to the predominant one in Western cultures, according to which humans have evolved from animals, while remaining animals in essence. For some Amazonian peoples, on the contrary, nonhuman animals and plants, which were human beings in primordial times, continue to be human, but in a different outer guise. The novelty of Santos-Granero's (2009) stance is that he includes artefacts along with animals and plants, sharing a primordial "humanity" with living beings.

According to Viveiros de Castro (2004, pp. 43f.), the idea of agency in Amazonia features both subjectivations, which involve treating things as human beings (with subjectivity), and objectivations, which consists in conceiving of the human body as an artefact. Children are often said to be treated as artefacts like blowguns and pots. Indeed, artefacts are often described by the makers as their "children". Some groups even use the same designation for the process of pregnancy and the fabrication of artefacts. In this line of thinking, the makers and their artefacts are related in terms of filiation.

On the basis of research conducted by prominent anthropologists concerned with the understanding of Amazonian worldviews, it may appear as if this supports the research paradigm of material agency (see Section 2.1). Nevertheless, it is important to distinguish, in the first place, the participatory (emic) perspective, taken by such scholars as Viveiros de Castro and Santos-Granero, and the external (etic) point of view, offered, on one hand, by Malafouris, and, on the other hand, by various approaches in cognitive semiotics. There is no a priori reason for these perspectives to coincide. In the second place, Malafouris claims that artefacts have their own kind of agency (different from human agency), while Santos-Granero's interpretation of the Amazonian worldview supposes artefacts to have human-like agency, which amounts to animism (Santos-Granero, 2009, p. 2). Interestingly, Malafouris (2013, pp. 133ff) proposes fetishism as an alternative to animism. Nonetheless, both approaches describe the agency of things as being symmetrical to human agency.

Whatever the difference between animism and fetishism, they both clearly contradict the cognitive semiotic perspective presented in Section 2.2. On this account, we are dealing here with worldviews on two levels, on that of particular socio-cultural life-worlds, commonly termed cosmologies, and on that of different scholarly perspectives, usually called epistemologies. Only detailed further philosophical and scientific research could tell us who is right or wrong on the second level. As a step in this process, we use a close study of Amazonian 
data, and analyse it through the prism of cognitive semiotics, as described in the following sections.

\section{The design and manufacturing of artefacts in Amazonia using pre-Columbian techniques}

After reviewing the current debate on agency in Section 2 and presenting anthropological interpretations of Amazonian worldviews with respect to artefacts in Section 3, we discuss a case study of the process of design and manufacturing of artefacts in Amazonia in order to explore the nature of such a process, and to investigate what it implies for understanding the agency of things. In this sense, the article aims to offer plausible (supported) interpretations to achieve interpretive distinctiveness (Tashakkori \& Teddlie 2003, p. 41). Although the fieldwork produced an extensive database, for the sake of brevity we only include the strictly necessary examples to support the main argument.

\subsection{General background}

The capability to plan, imagine, and improve artefacts, by means of the intentional shaping and assembly of materials, is a manifest expression of human agency. Moreover, design in the full sense of the term is arguably part of what constitutes human uniqueness (Davidson \& McGrew, 2005; Richerson \& Boyd, 2005; Hovers, 2012; Vaesen, 2012; Malafouris, 2013, p. 154; Buskes, 2019; Stout et al., 2019; Mendoza-Collazos, Zlatev, and Sonesson, in press). For example, after comparing different cognitive capacities for tool making of human and nonhuman primates, Vaesen (2012, p. 216) concludes:

Only human animals have been able to produce complex technologies (...) this remarkable feature reflects a profound discontinuity between us and nonhuman primates in matters of social and non-social intelligence.

In the peer commentary with the title "Human tool behaviour is species-specific and remains unique", Cachel (2012, p. 222) adds support for this claim:

Human tool behaviour is species-specific. It remains a diagnostic feature of humans, even when comparisons are made with closely related non-human primates. The archaeological record demonstrates both the deep antiquity of human tool behaviour and its fundamental role in distinguishing human behaviour from that of nonhuman primates.

Therefore, human "tool behaviour", and in particular the activity of designing, is a useful example to further the study of the relationship between human beings and artefacts, and to discuss the agency of things. Our study focused on artefacts made with pre-Columbian techniques in Amazonia. This context - claimed by some to be strongly animistic, as shown in Section 3 -can provide an ideal case for the study of the relation between design and the agency of things. The importance in focusing on pre-Columbian techniques lies in the possibility to minimize the bias from the current practice of design in industrialized societies.

The Amazon rainforest corridor extends from west to east in the middle of South America, covering 9 countries: Ecuador, Peru, Bolivia, Colombia, Brazil, Venezuela, Suriname, Guyana, and French Guiana. Geopolitical division of borders does not correspond to traditional settlements of Amazonian peoples. Most indigenous peoples are currently undergoing a process of Western acculturation or urban assimilation. Some natives have decided to live in isolation but none hold the status of being "uncontacted". The selected locations for observations were an indigenous reservation called Mocagua, and the city of Leticia, the capital of the department of 
Amazonas in Colombia, in the most southern corner of the country (see Figure 1). Mocagua is located $60 \mathrm{~km}$ from Leticia, on the banks of the Amazon River.

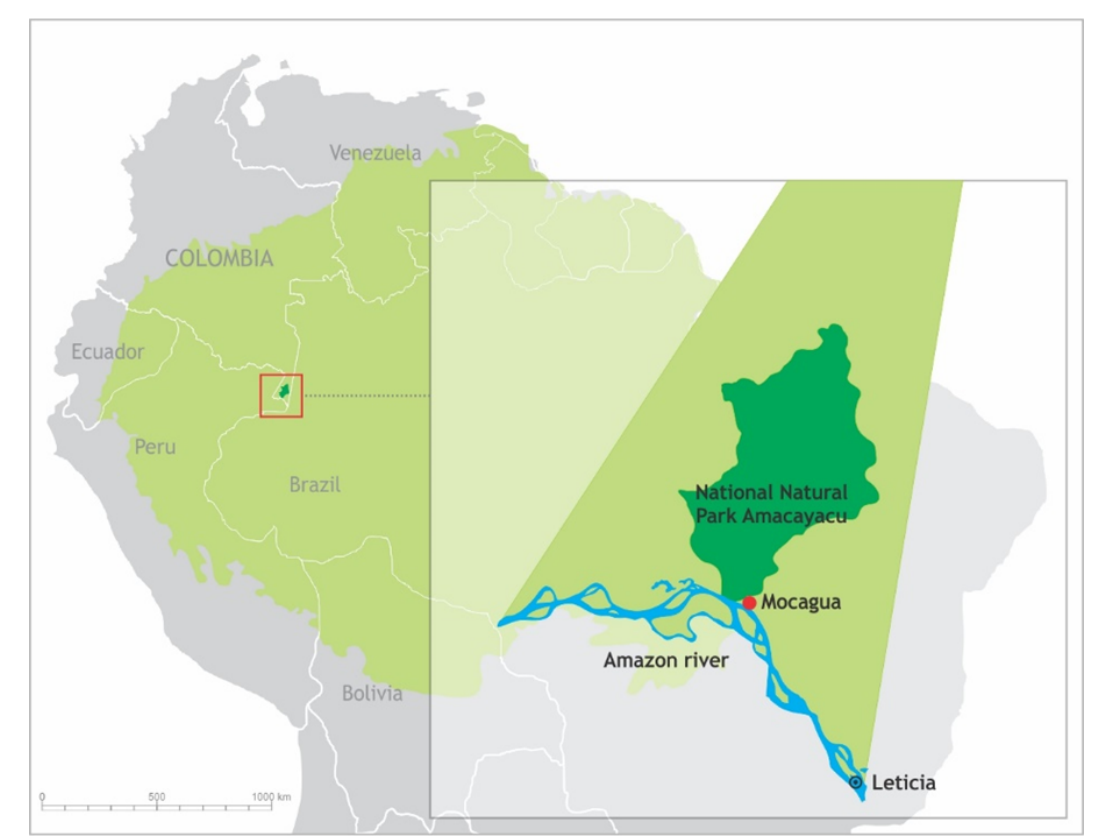

Figure 1. Location of Mocagua (an indigenous reservation) and Leticia in Amazonia; map produced by the first author based on Geocentric Reference System for the Americas and Geographic Institute of Colombia

\subsection{The Tikuna and their neighbours}

The Tikuna are an Amazonian people speaking a tonal language. A faction of Tikunas has decided to remain in isolation. They still produce artefacts using pre-Columbian techniques, especially for selling to tourists. Goulard \& Montes (2013) state that the Tikuna population consists of more than 60,000 individuals that are distributed between three countries (Colombia, Peru and Brazil). The term the Tikuna people use for themselves is Magüta, while Tikuna is a nickname that neighbours and enemies applied to them because of their custom of painting their skin black in ceremonial occasions, given that "tikuna" is a word from the Tupi language family, meaning "men painted black" (Nimuendajú 1952, pp. 108, 109, 128).

The Tikuna are famous for their mastery in using blowguns with lethal poisons. More recently hunting has largely been abandoned in favour of fishing. The reason for this change is a forced displacement of the Tikuna during their history, and the replacement of blowguns by shotguns. Sullivan (1970) writes that the Tikuna were able to throw the lances "as far as twenty metres ahead of the boat" and that "/i/nterestingly enough, large numbers of fish were taken this way" (Sullivan, 1970, p. 143). This ability is becoming rarer due to new techniques such as fishing rods and traps.

The Huitoto are neighbours of the Tikuna. The two peoples have had different types of relationships throughout history, from times of cruel wars to minimal contacts (García, 2016, p. 41). The Huitoto is an Amazonian people known as the "children of tobacco, coca, and sweet cassava". Their eponym is Murui-Muinane, which means "people from the west" (murui) and "people from the east" (muinane). They inhabit the southern zone of the Colombian Amazon and their population exceeds 6,000 people. They speak the Huitoto language that has several dialects. The Huitoto managed to remain isolated from the colonial system and from state 
control until the beginning of the 20th century. They carry out activities such as agriculture, hunting, fishing and harvesting of wild fruits, performing various rites for the collection of peanuts, planting and hunting (ONIC, 2020). According to Buinaje, a member of the Huitoto ethnic group: "The traditional management of the territory and the ecological calendar have always existed, in the blood, in the memory and in the daily actions of the children of tobacco,

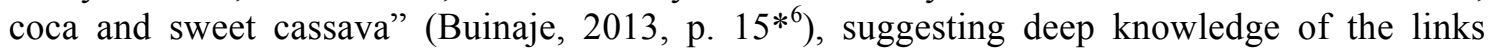
between material and nonmaterial spheres of the world. The Tikuna, the Huitoto and other indigenous peoples in the area are currently also more or less fluent in Spanish.

\subsection{The maloca}

The maloca is the most common type of house in native Amazonia. It determines control, planning and use of territory. In addition, the design of the maloca is based on cosmological principles, representing the native worldview. In Amazonia, ancestral housing involves a gender-based distribution of spaces and activities. Men are in charge of hunting, fishing and activities such as rituals, dances and leadership, while women are responsible for childcare, planting food, and cooking. ${ }^{7}$ A common distribution of the spaces in the maloca is shown by von Hildebrand (1983, p.203, see Figure 2).

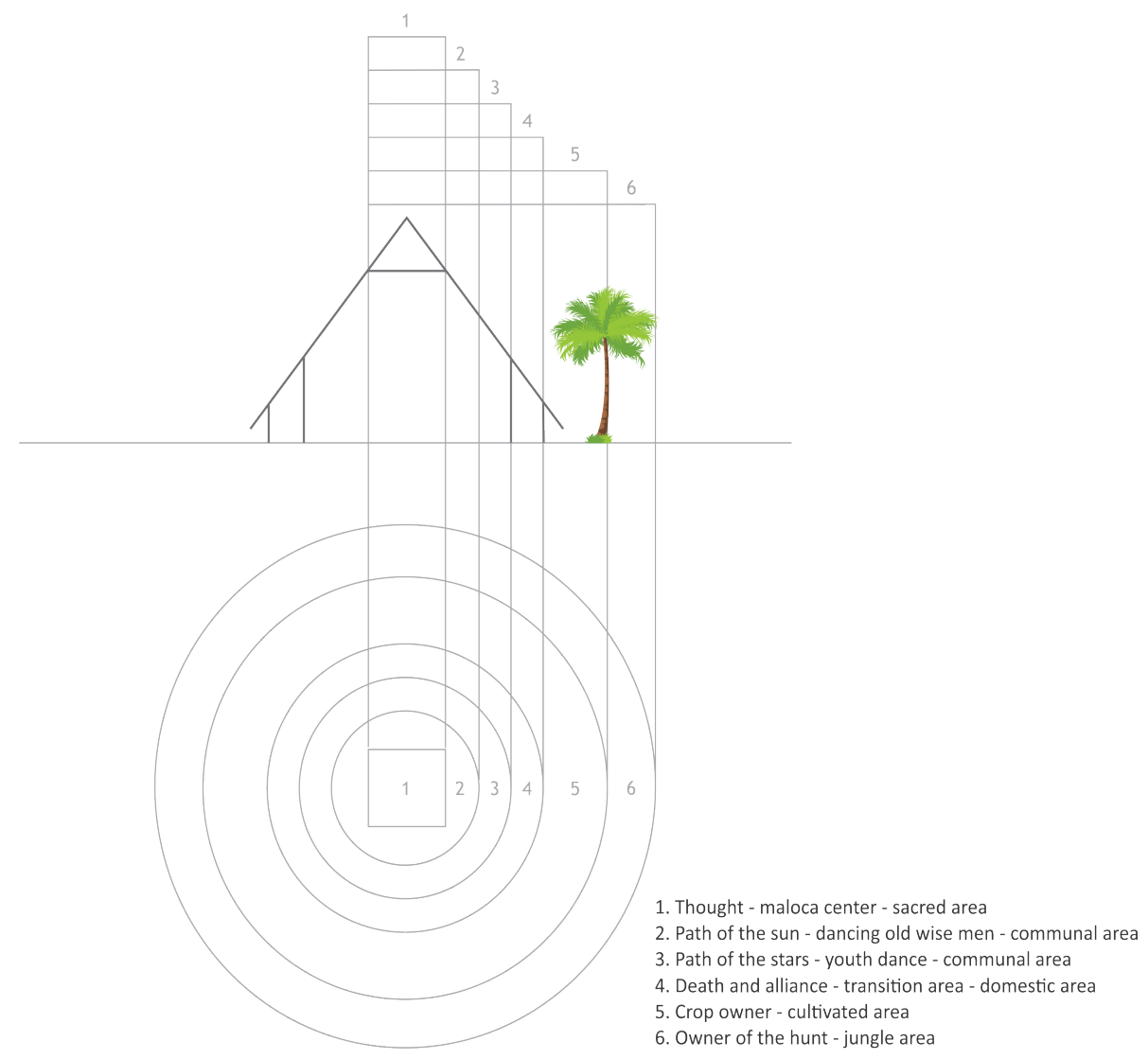

Figure 2. Top and front projection of a common distribution of malocas in zones with a gender-based distribution of activities; adapted from von Hildebrand, 1983, p. 203

\footnotetext{
${ }^{6}$ The asterisk henceforth indicates our translation from Spanish.

7 From our contemporary point of view, this delegation no doubt seems discriminatory, but for many Amazonian natives it may be conceived of as equitable in the sense of giving equal importance to the genders despite their different responsibilities.
} 
There are several different kinds of design of malocas in Amazonia, which are structured according to the particular worldview of each people. The Huitoto-type of maloca has "a sacred, masculine area" (Pineda et al. 2014, p. 104) dedicated to nocturnal gatherings which is called mambeadero. The zone is sacred because it is reserved for the sharing of ancestral beliefs: "The wisdom of the creator for his children is manifested in the three sacred elements of our culture: coca, tobacco and sweet cassava" (Buinaje, 2013, p. 15*).

In the mambeadero, an Elder dominates the dialogue while consuming concoctions of sacred plants such as mambe, tobacco and ambil. Mambe is a green powder made of coca (Erythroxylum coca) and yarumo (Cecropia). A small quantity of the powder is slowly dissolved in the mouth and swallowed. Tobacco (Nicotina rustica) is smoked directly from rolled tobacco leaves. Ambil is a paste made of tobacco and alkaline salts to be sucked in small quantities. Tobacco and coca are thought to open the gates for the invocation of ancient spirits; the consumption of these sacred plants facilitates the good speech of the Elder (Nieto \& Echeverri, 2013, p. 182).

\subsection{Methods and consultants}

The first author conducted fieldwork in the early 2020, participating in various indigenous activities, while focusing on artefacts and material culture. In spite of the fact that the fieldwork was cut short after three weeks due to the COVID-19 pandemic, the preliminary findings are sufficiently suggestive to merit consideration with reference to the Amazonian understanding of agency.

The methods for data collection were based on participant observation and interviews. The first author used fieldwork forms specially designed for systematic data collection, field notes, and voice notes. After presenting the purpose of the study to consultants ${ }^{8}$, informed consents (recorded in audio files) were obtained. Ongoing conversations were mixed with preestablished questions, according to the following general queries: How do you manufacture the artefact? How does it work? How did you learn to do it or how do you teach to do it? Who is the designer? Do you have a prior idea of the artefact's form? Are you allowed to introduce original features (innovations) in the design of the artefact?

A session of participant observation was conducted during the process of demolition and rebuilding of an urban maloca. The Council of the United Indigenous Peoples of Leticia (CAPIUL) built the maloca in the centre of Leticia City. Questions were addressed to the Elder, as the leader of the council. In addition, workers building the maloca gave details about traditional construction techniques and materials.

Observations of the Tikuna were focused on fishing with traditional artefacts (canoe, lances and paddles) in the flooded lands of the jungle and using pre-Columbian artefacts such as blowguns, boats, cookware, musical instruments and ritual outfits in a contextual-engaged environment. The pre-established questions were asked during ongoing conversations with the members of a particular Tikuna family.

Adopting the conceptual-empirical loop of cognitive semiotics (see Section 1), we analysed the material gathered through the fieldwork, by alternating between a more distanced etic perspective (regardless of the beliefs and habits sedimented through time in Amazonian worldviews) and an emic perspective which was more useful for data collecting, and for acquiring a deeper understanding of the worldviews of any specific people.

\footnotetext{
${ }^{8}$ The term "consultant" reflects the fact that natives are the true experts in the knowledge and experiences about their own culture, so we use the term rather than "participants". We are thankful to Simon Devylder for pointing this out.
} 


\subsection{Findings and discussion}

The study showed that the design process of artefacts among the Tikuna and their neighbours in Amazonia is strongly based on tradition. The design pattern is conceived of as being granted by the mythical creators, thus having a cosmological origin. The Elder, for example, sits on an exclusive sacred stool called pensadero (thinking stool) with a special design and decoration (see Figure 3). The stool has a dedicated location close to the maloca's main pillar. The consultants reported that the design of the stool is meant to shape the body position into a thoughtful attitude, similar to how this was described by Buinaje (2013, p. $73 *)$ : "This man sitting on his stool is the symbol of the highest educator, this attitude means reflection, concentration, thought, direction, dialogue, knowledge, spiritual control, standards of conduct, teaching and power of service"

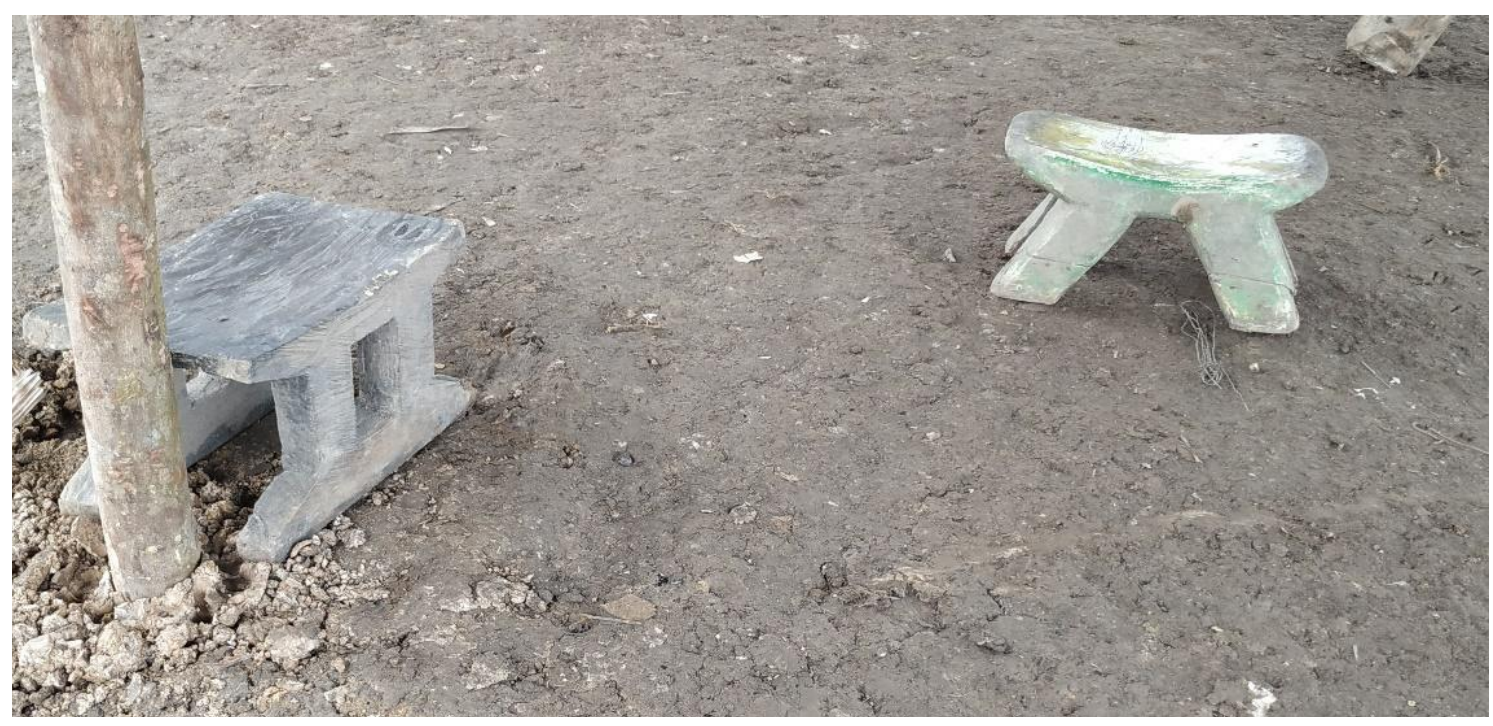

Figure 3. Thinking stool (left). Notice the special design of the exclusive stool for the Elder. A conventional design of the stool (for guests) appears at right; photo by the first author

The consultants described the design origin of malocas as a process similar to the one reported by Whiten $(2019$, p. 333$)$ with reference to simple artefacts. Individual learning is based on multiple episodes of observation along with episodes of practice with a "copy all, refine later" strategy. The process of innovation with refinements may be regarded as the essence of design, which can be made by individuals, or over time between different generations of technological development. When asked about the origin of the maloca, the Elder explained it as a progressive improvement from a simple structure to a complex and innovative design: ${ }^{9}$

(...) They were shamans and said, "how are we going to live in a world like this? We have to settle down." Then, they did the ritual to manage the world. They did a simple malocashaped structure like this [the Elder is drawing on the ground], as a triangle. They went to the Uncle and said:

"Look Master, we are doing a maloca."

"Right nephew? But let's see how you did the design, explain how you did it."

"We made the design like this: here we erected one pillar, we erected the other one here, like this."

"Ah, this is not a maloca, it is different." That was the one created for Tikuna.

\footnotetext{
9 This is a short fragment of the original narration, given by the Elder in Spanish. The complete transcription appears in Appendix A, including the explanation of weaving palm-leaves to make the maloca roof and how this knowledge was transferred to people.
} 
So, they made another maloca design. They went to the Uncle. "That is not maloca," he said.

Later they made another one, similar to the previous one, but the shape was like this: here they took out pillar, pillar, pillar [drawing on the ground]. The master said, "That is not a maloca", and they gave this one to other people.

"Let's see, let's do the maloca now," said the four masters. So, they did the maloca with a long pillar in the middle and twelve short pillars around it. "You are about to do a real maloca", said the master. So, they made a bigger maloca from the previous design.

"What you've done is the management of the created jungle. You already have experience. So, I am going to give you permission to make malocas."

You have to pass through all that process that the masters did. So, to begin with, it was the little maloquita, then becoming bigger and bigger, as their knowledge grew. If you do a maloca without permission and training, you will be cursed. The weight of the maloca will overcome you. And so was all maloca creation. For us, all things have an origin. Everything has an origin, why does that exist? What principle? What function? How do they contribute to the balance of nature? Everything serves in nature, everything contributes.

What is clear here is that the artefact, in this case the maloca, is not conceived of as an agent in its own right, as could be expected from the descriptions of the Amazonian animistic worldview summarized in Section 3, and more generally from the idea of a symmetrical part played by artefacts in the interaction with people. Rather, the Elder here describes a process in which the maloca is created by the concerted efforts of a number of human or humanlike agents. Thus, we have a clear case of generative sedimentation (see Section 2). That is, the maloca is seen as an object which is the result of a number of meaning-bestowing acts accomplished by other agents in the past. Whether these agents are considered to be gods, shamans, or wise-men living in an earlier age is not important here. They are clearly conceptualized as human beings. This would even be true if the creators of the maloca had been claimed to be animals, given the idea of animals as human beings in disguise.

The Elder's description of the origin of the maloca is remarkable in several other ways. First, it is clearly a recipe for creating malocas. Second, it describes a trial-and-error process which, is likely to be familiar to contemporary designers. Third, there is nothing in the retelling of the story that posits "the Uncle" as being in any sense otherworldly, as often taken for granted in classical accounts. The Uncle may just as well only be a person many generations apart from the present. Nevertheless, there is, of course, a difference between the ancestral Uncle telling you what is right and wrong, and a contemporary designer doing the same. ${ }^{10}$ The design process is extended through generations until the origins of time, thus attributing a cosmological nature to the design. Innovations are therefore restricted, with novel design features deriving from mastery and finesse of pre-Columbian techniques. The design process appears to aim to produce optimal and essential artificiality, one that endures through time and contributes to the balance of nature.

What the Elder describes is not only a story about the origin of the maloca, but a blueprint for creating new instances of the maloca type. In this respect, his description is reminiscent of Husserl's (1954) analysis of geometry being the result of the sedimentation of the practice of land surveying. A closer analysis than that offered by Husserl might posit an intermediate stage between the primordial act of land surveying and geometry, which would consist in establishing a recipe book of land surveying, prior to the recipe book which we call geometry (Sonesson, to appear a, b). In the same way, what the Elder here offers is a recipe book for the construction of malocas.

The notion of sedimentation is also evident in the explanation of design origins for Tikuna ritual masks. In the excerpt below, a member of the Tikuna people was planning an

\footnotetext{
${ }^{10}$ Another issue, into which it would have been interesting to delve, is the fact that many of the failed tentatives happen to result in the malocas of neighbouring peoples. This is an observation of interest to the semiotics of culture (e.g. Sonesson, 2012).
} 
ethnographic museum in the Mocagua reservation. This allowed the researcher to scrutinize painted textiles, blowguns, fans, basketry, pottery, musical instruments, ritual garments, and masks while the consultant answered the questions on design issues. In relation to the design of masks he explained:

Here, there are no previous drawings, but there is a prior idea. For this [pointing to the mask] it has to be said "I have this ritual and I need you to tell me how I should represent these deities." Therefore, you already know what to draw beforehand, there is already communication that comes from cultural learning for a long time ago (...) So, you don't make the mask as you wish. The owner of nature, the owner of time, the owners are warning you, they are making you see what is to be represented.

I called it a "museum", but it really is a learning centre. Objects mean many things: the origins, moral advice, songs and stories behind the object. The importance is in the living knowledge. There is little research on these things (...) At night they narrate how the origin of things was. [The narration] is a way of explaining things, a language that tells us that behind the artefact itself there are many things, norms, laws, physics, mathematics, geometry. (Appendix B*).

Explanations such as this, referring to accumulated knowledge, also suggest that the possession of an artefact or the artefact itself is not essential. What is really important is the knowledge behind it: both its technique and its purport. It is the question of the mastery of the manufacturing technique, the ability to use the artefact - the art of hunting with blowguns or playing the drums properly, for instance - and the capability to understand the purport of its design. The consultant repeatedly alluded to these ideas, with expressions such as: "the importance is in the living knowledge"; "It is not a simple thing, there is a message there. It is not the object that matters. After the ritual, it is discarded"; or "the mask is a whole. If you acquire those things separately, it does not have any meaning" (see Appendix B*).

As revealed in the field study, things are used as products of human agency, but the artefacts themselves are expendable, since what is really important is the agentive dimensions of users: actions, beliefs, knowledge, identity, intersubjectivity and so on. This finding is congruent with the interpretation by Ewart (2012, p. 178) in her study on Panará beadwork, focusing on the intersubjective relations mediated by the exchange of beads and the notion of reciprocity:

Beyond that, the sociability involved in sitting together and making things is a fundamentally important aspect of how and why certain material goods come to be particularly valued. Against this background, the immutable qualities of material goods as enduring objects in their own right recede in significance.

Elsje Lagrou also offers interpretive consistency with our findings: "More important than the things themselves is the knowledge of how to make things" (Lagrou, 2009, p. 208).

\section{General discussion}

As we noted in the introduction, many prominent scholars in the human and social sciences have been arguing that not only other living beings, but also material artefacts stand in a reciprocal relation to human beings with respect to agency that is symmetrical. From a perspective grounded in cognitive semiotics and phenomenology, and based on the evidence presented in the previous section, such a "consensus" is not warranted; neither from a theoretical nor an empirical point of view. Agency proper should not be confused with the cognitive strategies employed by human beings to treat artefacts as persons, as in the cases described in Section 3. Endowing artefacts with various kinds of meanings and practical 
functions is the process in which a true agent assigns agency to artefacts by means of design. As a result of this process, artefacts acquire a form of derived agency, in line with the approach presented in Section 2.2, and contrary to the approach of material agency (Section 2.1).

Derived agency allows artefacts to mediate interactions between true agents, to enhance the agent capabilities for action, and to achieve the purposes of the agent. In this sense, the relation is clearly asymmetrical. This is illustrated by an example given by Halbmayer (2018, p. $195 *)$ :

The arrows are adorned with the snake's look. They become the snakes of the hunter. These ornaments are also blunt signs of individuality (...) Knowing that the arrows are possessed objects and extensions of the person; people not only appear like snakes and they look like snakes, also they have their artificial snakes, namely, their arrows, with which they can kill and hunt.

Here, the agent is shown to assign agentive features of the snake to the arrow; that is, the design of the arrow is inspired by the snake with the goal of accomplishing the purpose of the hunter. Thus, the arrow has been endowed with derived agency by means of designing. The process adds features guided by the purpose of the hunter and inspired by the agency of the snake, expanding the agentive capabilities of the hunter. The aim of design is to extend and enhance human agency by means of prosthetic incorporation of artefacts. We propose to call this special form of derived agency enhanced agency.

In sum, derived agency is a kind of agency assigned by proper agents to artefacts by means of design. Original agency refers to the capabilities of proper agents for action without the incorporation of artefacts, a kind of bare agency, which also many non-human animals possess. Throughout evolution, our ancestors improved the capabilities for tool-making by means of biocultural coevolution (Donald 1991; Richerson \& Boyd 2005; Mendoza-Collazos, Zlatev \& Sonesson, in press). While bare agency is intrinsic, to some degree, to all animals (Zlatev, 2009; 2018), the unique ability to continually improve artefacts allows human beings to assign derived agency to things by means of design. Thus, we alone on this planet possess enhanced agency through prosthetic incorporations of artefacts added to their original agentive capabilities. ${ }^{11}$ At the same time, we should acknowledge that there is a continuum between original and enhanced agency in actual human practice, as in evolution. Still, a conceptual distinction between the two needs to be maintained.

The transition from original (bare) agency to enhanced human agency was clearly evident in the data from the fieldwork. For instance, a Huitoto consultant explained that the manguaré (ritual drums) allow natives to communicate over long distances, as a kind of ancestral GPS (see Appendix C).

The design of manguaré is intended to produce a profound sound that can spread over long distances, allowing the hunter to locate the village again:

Well, inside the maloca we have this instrument called manguaré. Manguaré is very sacred to us. (...) We use the manguaré only for rituals, for funerals, to call people who are at work and to locate people who are lost in the jungle. That is why the person who plays this instrument must be chosen by the Elders. No one else can touch or lean on it. (...) Behind the manguare there is a series of advice, teachings, and practices. For example, the practice of elaboration, because manguaré has precise techniques (...) There is a lot of knowledge behind. (fragments from Appendix $\mathrm{C}^{*}$ )

\footnotetext{
${ }^{11}$ It is interesting to notice that, in the case of agentive capabilities different from the standard (for instance a person that has suffered the loss of a limb, a phenomenon studied by Pielli \& Zlatev (2020), the incorporation of artefacts helps to restore the agency concerning the use of such limb.
} 
In this case, according to animistic explanations, the drums possess supernatural agency becoming a sacred object for the natives with powerful humanlike communicative skills (Santos-Granero, 2009, p. 10). In contrast, we propose that the incorporation of drums into the natives' communicative capabilities enhances human agency; therefore, the original agentive capability for communicating develops into an enhanced agency with possibilities of communication beyond human standards. The drums do not possess the ability to communicate themselves. Rather, they depend on a set of remote intentions, explaining the need to produce the artefact. The derived agency of manguare is manifested by their impressive ability to spread sounds, which was assigned to them through designing and depends on the true agents (the native people) playing the drums to work.

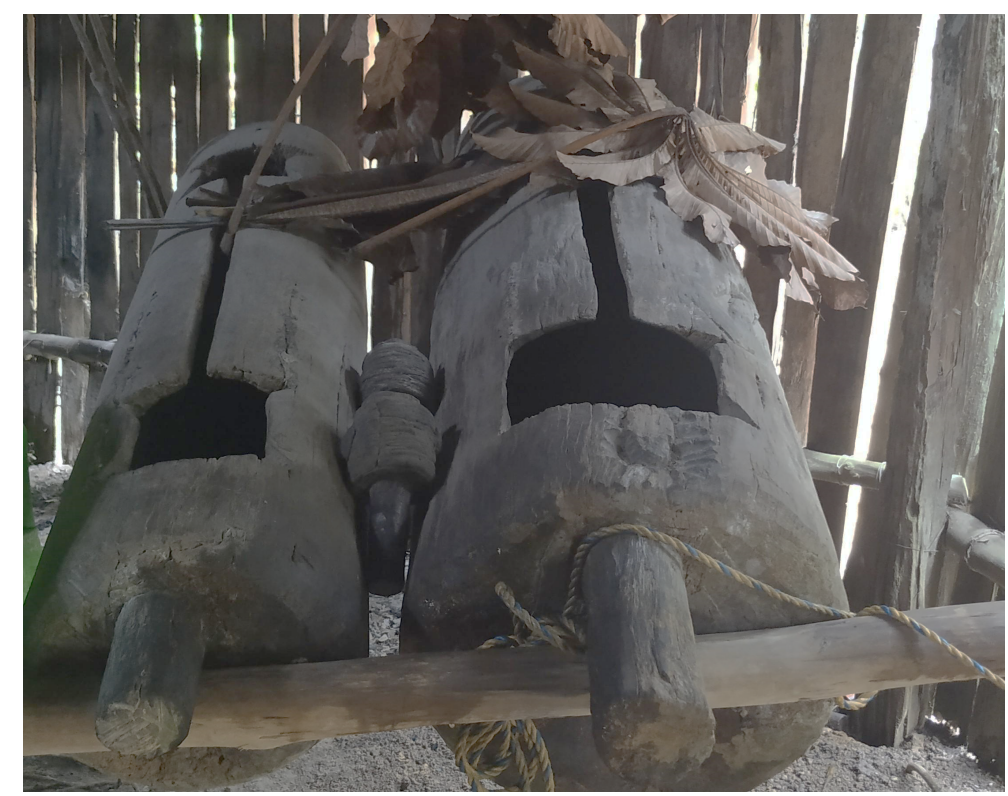

Figure 4. Manguare drums at the entrance of the maloca. It is the most important artefact in the maloca and a good example of enhanced agency; photo by the first author

The findings in relation to house building demonstrate the set of remote intentions that explain the maloca design. For instance, the need to manage the seasons for plantations by means of a solar calendar; or the intention to preserve the social structure by means of the distribution of space. The solar calendar expresses the capacity of the architectural disposition to transmit information, but again, such capacity is derived and depends on their users to endow it with significance.

The process of design and continuous improvement of malocas from their ancient origins, as recorded in the oral tradition, reflect the unique way of making artefacts of human beings allowed by the process of sedimentation. From the first intention, that is, the start of the consultant's narration, "They were shamans and they said how are we going to live in a world like this? We have to settle down", a set of remote intentions were apparently accumulated on the improved design of malocas through time.

As against the currently popular (methodological or not) animistic/fetishist explanations of our interactions with artefacts, the notion of enhanced agency serves to emphasize the fact that these interactions are modified in important ways by the artefacts, while still sustaining a difference between true agents and artefacts. Thus, the notion of enhanced agency is opposed to approaches to the agency of artefacts, such as that of Malafouris (2013) and Santos-Granero (2009). On the one hand, it opposes a position which would underplay the importance of things, 
endowing them only with a functional (instrumental) character, while overlooking their role in creating new relations of meaning between the agent and the world. On the other hand, it also rejects the material agency position which downplays the fundamental differences between living and non-living entities.

Our proposal emphasizes the importance of both agents and things, as Malafouris' approach does, while, at the same time, positing an asymmetrical relationship between artefacts and human beings, as a result of taking into account the difference of their ecological relationships. Most theories that tend to give agency status to artefacts overlook the process of design, starting from the things already present in the world. Guided by the evidence collected in the fieldwork in Amazonas, we wish to highlight the role of design as a feature strongly impacting the nature of human agency, unique for our planet (Tallis, 2011).

\section{Conclusions}

In this article, we have presented a cognitive semiotic explication of the relationship between artefacts and human beings in relation to agency. Our aim has been to address the agency of things from a phenomenological perspective grounded in contextually-engaged observations, while focusing on the process of design and manufacturing of artefacts using pre-Columbian techniques as currently still practised by indigenous peoples in Amazonia. Scholarly interpretations of Amazonian cultures frame these peoples' worldviews in terms of different approaches to animism and fetishism, which are problematic, especially in relation to things. Therefore, the context of Amazonia seems to provide an optimal field to rethink such approaches.

The cumulative improvement of artefacts by means of designing is a unique feature of human cultures. Many animals are capable of making tools, but only human beings can improve the technology of creating artefacts, as well as extending their functions (e.g. Donald 1991). Therefore, we considered design to be a fruitful point of departure for discussing the features of human agency and the derived agency of things.

We have discussed two currently conflicting approaches to the agency of things. As a representative of the first, the theory of material agency proposed by Malafouris (e.g. 2013) claims that humans endow artefacts with material agency by means of fetishization, which is in line with animistic interpretations of Amazonian worldviews concerning artefacts. On this take, the relationship between people and things is symmetrical, in the sense that the agency of things is of equal importance as the agency of human beings. In contrast, in the second approach, the agency of things is assigned to objects by human agents by means of the process of designing, making it derived and asymmetrical, because it depends on the agent's actions and intentions. In this approach, the attribution of derived agency to artefacts allows persons to expand their own agency. We have proposed the notion of enhanced agency as a characterization of this phenomenon, corresponding to the prosthetic incorporation of artefacts into the physical and cognitive abilities of agents, in order to enhance the capabilities of action of true agents beyond those afforded by bare agency.

The evidence from the fieldwork by and large supported the second approach, emanating from the new discipline of cognitive semiotics. In the rain forests of Amazonia, indigenous peoples like the Tikuna were shown to assign functions and shapes to materials, endowing artefacts with derived agency, very well understanding that artefacts cannot act on their own. The sedimented semiotic actions of design are often translated into narrations as a strategy to preserve the knowledge and traditions. Much more research is needed in order to explain the agency of things, but the present study strongly suggests that in order to make progress, we have to go beyond both traditional and currently fashionable notions like fetishism and animism, and rather adopt an overarching phenomenological approach, which implies a return to experience and observed reality. 


\section{Acknowledgments}

The first author expresses his deepest gratitude to consultants from Leticia and Mocagua indigenous reservation for their selfless and open collaboration. $\mathrm{He}$ is also grateful to the Amazonia campus of Universidad Nacional de Colombia, and particularly to the professors Abel Santos, Edgar Bolívar and Carlos Franky for facilitating his introduction to the field. We would also like to thank Anna Cabak-Redei for her help with this study at its initiation. Finally, we are grateful to the two anonymous reviewers for their insightful comments, and to the editor Jordan Zlatev for issues of structure and style.

\section{References}

Adams, F. and Aizawa, K. (2001). The bounds of cognition. Philosophical psychology 14(1): 43-64.

Blomberg, J. (2019). Interpreting the concept of sedimentation in Husserl's Origin of Geometry. Public Journal of Semiotics 9(1): 78-94.

Buinaje, A. (2013). La maloca Uitoto como espacio educativo de vida desde los principios tradicionales del clan Eimen+ de la etnia Uitoto de La Chorrera, Amazonas, Colombia Thesis. La Chorrera: Universidad Pedagógica Nacional.

Buskes, C. (2019). The encultured primate: Thresholds and transitions in hominin cultural evolution. Philosophies 4(1), 6: 1-16. http://dx.doi.org/10.3390/philosophies4010006

Cachel, S. (2012). Human tool behaviour is species-specific and remains unique [Peer commentary]. Behavioral and Brain Sciences 35: 222.

Clark, A. and Chalmers, D. (2010). The extended mind. In R. Menary (Ed.). The extended mind (pp. 27-42). Cambridge: The MIT Press.

Cowley, S. and Vallée-Tourangeau, F. (2013). Cognition beyond the brain: Computation, interactivity and human artifice. London: Springer.

Davidson, I. and McGrew W. (2005). Stone tools and the uniqueness of the human culture. $J$. Roy. anthrop. Inst. 11: 793-817.

Descola, P. (2005). Par-delà nature et culture. Paris: Gallimard.

Donald, M. (1991). Origins of the modern mind: three stages in the evolution of culture and cognition. Cambridge: Harvard University Press.

Ewart, E. (2012). Making and unmaking Panará beadwork-Or, how to overcome the fixity of material things. Anthropology and Humanism 37(2): 177-190.

García, O. (2016). Danzando fakariya: los bailes uitotos como modelo de organización social en la Amazonía. Bulletin de l'Institut français d'études andines 45(1): 39-62.

Goulard, J. and Montes, M. (2013). Los yurí/juri-tikuna en el complejo socio-lingüístico del noroeste amazónico. Línguas Indígenas de America do Sul, LIAMES 13: 7-65.

Halbmayer, E. (2018). Los escritos de los objetos: hacia una textualidad material entre los yukpa. Mundo Amazónico 9(1): 173-202. http://dx.doi.org/10.15446/ma.v9n1.64361

Hildebrand, M. von. (1983). Notas etnográficas sobre el cosmos Ufaina y su relación con la maloca. Maguaré 2: 177-210.

Hovers, E. (2012). Invention, reinvention and innovation: the makings of Oldowan lithic technology. In Elias S. (Ed.). Origins of human innovation and creativity. Amsterdam: Elsevier.

Husserl, E. (1939). Erfahrung und Urteil. Prag: Academia Verlagsbuchhandlung.

Husserl, E. (1954). Die Krisis der europäischen wissenschaften und die transzendentale phänomenologie: eine einleitung in die phänomenologische philosophie. Husserliana: Gesammelte Werke VI, 2nd ed. Haag: Nijhoff.

Husserl, E. (1973). Husserliana: gesammelte Werke. Bd 15, Zur Phänomenologie der Intersubjektivität, T. 3 : 1929-1935 : Texte aus dem Nachlass. Haag: Nijhoff. 
Husserl, E. (1974). Husserliana: gesammelte Werke. Bd 17, Formale und transzendentale Logik. Haag: Nijhoff

Hutto, D. D. and Myin, E. (2013). Radicalizing enactivism. Basic Minds without Content. Cambridge: MIT press.

Hutto, D. D. and Myin, E. (2017). Evolving enactivism: Basic minds meet content. Cambridge: MIT press.

Knappett, C. and Malafouris, L. (2008). Material and Nonhuman Agency: An Introduction. In C. Knappett and L. Malafouris (Eds.). Material agency; towards a non-anthropocentric approach (pp. ix-xviii). New York: Springer.

Lagrou, E. (2009). The crystallized memory of artifacts: a reflection on agency and alterity in Cashinahua image-making. In F. Santos-Granero (Ed.). The occult life of things: native Amazonian theories of materiality and personhood (pp. 192-213). Tucson: The University of Arizona Press.

Latour, B. (1993). We have never been modern. Cambridge: Harvard University Press.

Latour, B. (2005). Reassembling the social. An introduction to Actor-Network Theory. Oxford: Oxford University Press.

Malafouris, L. (2008). At the potter's wheel: an argument for material agency. In C. Knappett and L. Malafouris (Eds.). Material agency; towards a non-anthropocentric approach (pp. 19-36). New York: Springer.

Malafouris, L. (2013). How things shape the mind: a theory of material engagement. Cambridge: MIT Press.

Mendoza-Collazos, J. (2015). Semiótica del diseño con enfoque agentivo: Condiciones de significancia en artefactos de uso. Bogotá: Utadeo.

Mendoza-Collazos, J. (2016). Design semiotics with an agentive approach: an alternative to current semiotic analysis artefacts. In J. Zlatev, G. Sonesson, and P. Konderak (Eds.) Meaning, Mind and Communication - Explorations in Cognitive Semiotics (pp. 83-99). Frankfurt am Main: Peter Lang Edition.

Mendoza-Collazos, J. (2020). On the Importance of Things: A Relational Approach to Agency. Cognitive Semiotics 13(2). https://doi.org/10.1515/cogsem-2020-2034

Mendoza-Collazos, J., Zlatev, J. and Sonesson, G. (in press). The origins and evolution of design: A stage-based model. In E. Pagni and R. S. Theisen (Eds.). Biosemiotics. The Natural Foundations of Symbolism. Cham: Springer.

Merleau-Ponty, M. (1995). La nature. Cours de Collège de France, 1956-60. Établi et annoté par Dominique Séglard. Paris: Seuil.

Meyer, J., Dentel, L. and Seifar, F. (2012). A methodology for the study of rhythm in drummed forms of languages: application to Bora Manguaré of Amazon. Interspeech: 687-690.

Nieto, J. and Echeverri, J. (2013). 'Si esto fuera una maloca de por allá, pues fuera otra historia': La comunidad uitoto de Florencia, Caquetá. In J. C. Suárez Álvarez and C. G. Zárate (Eds.). Un río de saber: Investigaciones desde la Amazonia colombiana (pp. 159186). Leticia: Universidad Nacional de Colombia.

Nimuendajú, C. (1952). The Tukuna. Berkeley: University of California Press.

Niño, D. (2015). Elementos de Semiótica Agentiva. Bogotá: Universidad Jorge Tadeo Lozano

Organización Nacional Indígena de Colombia (ONIC). (2020). Los Tikuna. https://www.onic.org.co/pueblos

Pielli, L. and Zlatev, J. (2020). The cyborg body: Potentials and limits of a body with prosthetic limbs. Cognitive Semiotics 13(2).

Pineda, R., Morcote, G., García, H., Uribe, M. and Londoño, E. (2014). Ethnographic Museum: Leticia, Amazonas, Colombia. Bogotá: Banco de la República

Richerson, P. J. and Boyd, R. (2005). Not by genes alone: How culture transformed human evolution. Chicago: University of Chicago Press.

Rupert, R. (2004). Challenges to the hypothesis of Extended Cognition. Journal of Philosophy 101(8): 389-428. 
Santos-Granero, F. (2009). Introduction: Amerindian constructional views of the world. In F. Santos-Granero (Ed.). The Occult Life of Things: Native Amazonian Theories of Materiality and Personhood (pp. 1-29). Tucson: The University of Arizona Press.

Searle, J. (1979). The intentionality of intention and action. Inquiry 22(1-4): 253-280.

Searle, J. (1983). Intentionality: An essay in the philosophy of mind. Cambridge: Cambridge University Press.

Sonesson, G. (1999). Postphotography and beyond. From mechanical reproduction to digital production. VISIO 4(1): 11-36.

Sonesson, G. (2009). View from Husserl's lectern: Considerations on the role of phenomenology in cognitive semiotics. Cybernetics \& Human Knowing 16(3-4): 107148.

Sonesson, G. (2012). Between homeworld and alienworld: A primer of cultural semiotics. In Ernest W.B. (Ed.). Sign culture - Zeichen Kultur (pp. 315-328). Würzburg: Königshausen $\&$ Neumann.

Sonesson, G. (2015). From remembering to memory by way of culture. A study in cognitive semiotics. Southern Semiotic Review 5(1): 25-52.

Sonesson, G. (to appear a). The relevance of the encyclopaedia: From semiosis to sedimentation and back again. Semiosis in Communication: Differences and Similarities (in press). Berlin: De Gruyter.

Sonesson, G. (to appear b). The elucidation of the phenomenology of the picture sign from its phaneroscopy, and vice versa. Shafiei, M. and Pietarinen, A. (Eds.). Phaneroscopy and phenomenology: a neglected chapter in the history of ideas. Cham: Springer.

Steinbock, A. (1995). Home and beyond: Generative phenomenology after Husserl. Evanston: Northwestern University Press.

Stout, D., Rogers, M., Jaeggi, A. and Semaw, S. (2019). Archaeology and the origins of human cumulative culture: A case study from the earliest Oldowan at Gona, Ethiopia. Current Anthropology 60(3): 309-340.

Sullivan, J. (1970). The impact of education on Ticuna indian culture: An historical and ethnographic field study. PhD dissertation. Denton: North Texas State University.

Tallis, R. (2011). Aping mankind: Neuromania, darwinitis and the misrepresentation of humanity. Durham: Acumen.

Tashakkori, A. and Teddlie. C. (Eds.). (2003). Handbook of mixed methods in social \& behavioral research. London: SAGE.

Vaesen, K. (2012). The cognitive bases of human tool use. Behavioral and Brain Sciences 35: 203-218.

Viveiros De Castro, E. (1998). Cosmological deixis and Amerindian perspectivism. Journal of the Royal Anthropological Society 4(3): 469-488.

Viveiros De Castro, E. (2004). Perspectivismo y multinaturalismo en la América indígena. In A. Surrallés and P. García (Eds.). Tierra adentro: Territorio indígena y percepción del entorno (pp. 37-80). Copenhagen: IWGIA.

Ward, L. (2002). Dynamical cognitive science. Cambridge: The MIT Press.

Welton, D. (2000). The other Husserl: The horizons of transcendental phenomenology. Bloomington: Indiana University Press.

Whiten, A. (2019). Culture in the Stone Age. Current Anthropology 60(3): 333-334.

Zlatev, J. (2009). The semiotic hierarchy: Life, consciousness, signs and language. Cognitive Semiotics 4: 170-201.

Zlatev, J. (2015). Cognitive semiotics. In P. Trifonas (Ed.). International handbook of semiotics (pp. 1043-1067). Dordrecht: Springer.

Zlatev, J. (2018). Meaning making from life to language: The semiotic hierarchy and phenomenology. Cognitive Semiotics 11(1). https://doi.org/10.1515/cogsem-2018-0001 
Authors' addresses:

Email address: juan.mendoza@,semiotik.lu.se

Email address: goran.sonesson@semiotik.lu.se

About the Authors

Juan Carlos Mendoza-Collazos is an Associate Professor at Universidad Nacional de Colombia, and doctoral candidate in Cognitive Semiotics at Lund University. He currently investigates the role of artefacts in relation to agency with a cognitive semiotic approach. He is the author, among other texts, of the book Semiótica del diseño con enfoque agentivo: condiciones de significancia en artefactos de uso [Semiotics of design with an agentive approach: Conditions of significance in artefacts] (Utadeo, 2015), and the fifth chapter of the book Meaning, Mind and Communication: Explorations in Cognitive Semiotics, edited by Jordan Zlatev, Göran Sonesson and Piotr Konderak in 2016 (Frankfurt/M.).

Göran Sonesson is a semiotician specializing in pictorial, cultural, and cognitive semiotics. In recent years, he has also been concerned with the epistemology of semiotics, mainly on a phenomenological basis, as well as with an evolutionary foundation for semiosis. Apart from the books Pictorial concepts (Lund 1989), Bildbetydelser (Lund 1992) and Pictorial Extensions of Mind (forthcoming), Sonesson has published numerous articles in many anthologies as well as in journals such as Semiotica, VISIO, Sign System Studies, Degrés, RSSI, Signa, Signata, and Cognitive Development. He was one of the founders of the International Association for Visual Semiotics (AISV/IAVS) and has also been active in the boards of International Association for Semiotic Studies (AIS/IASS), the Nordic Association for Semiotic Studies (NASS), and the International Association of Cognitive Semiotics (IACS). 


\section{Appendix A}

Design origins of maloca

$\begin{array}{ll}\text { Interviewer: } & \text { First author } \\ \text { Interviewee: } & \text { An Elder } \\ \text { Date: } & \text { February 28,2020-13:51 } \\ \text { Place: } & \text { Leticia city } \\ \text { File name: } & \text { 200228_aa_maloca_design_2_rec_int-jmc } \\ \text { File location: } & \text { Fieldwork/data-collection/audio } \\ \text { Language: } & \text { Spanish } \\ \text { Translation: } & \text { First author }\end{array}$

For us, Yucuna, who had the design of the maloca was Sky, he is a person, he is the Master. He had the knowledge of how to build malocas. It turns out that he also had his nephews who were the four wise men who came after him. They called him the Uncle, because the sky and his sister made the world. The four masters were not born of any woman, of any person, of any man. That is why they were called children of living. The youngest of them is a creator, everything he did worked, everything he did was very well thought out.

They were shamans and they said "how are we going to live in a world like this? We have to settle down." Then, they did the ritual for healing, to manage the world, because for us managing the territory is done from the maloca space, in theory and practice. In theory you narrate, then dance, harmonize.

So, the four masters started, "we are going to make maloca, we are going to invent, we are going to consult with the Uncle. He is going to tell us if it is a maloca or not."

So, they did a simple maloca-shaped structure, as a little maloquita, like this (drawing on the ground), as a triangle. For example, I can tie here (indicating the corner knots of the maloca) as a triangle, that's what they did. They made the basic structure, no more. So, they went to the Uncle and said:

"Look Master, we are doing a maloca."

"Right nephew? But let's see how you did the design, explain how you did it."

"We made the design like this: here we erected one pillar, we erected the other one here, like this."

"Ah, this is not a maloca, that is different, for this one you can use platanillo leaves."

That was the one created for Tikuna, like a triangle and with a fallen leaf. So, they made another maloca design. They went to the Uncle.

"That is not maloca," he said, "how did they do that, that is a ranchito, that is not a maloca. For this you can use a milpesos palm."

And they chose that one for other people. Well, later they made another one, similar to the previous one, but the shape was like this: here they took out pillar, pillar, pillar (drawing on the ground).

The master said, "That is not a maloca, that is puadoka, the parrot's house, it is not a maloca. You can use bonbon leaves." And they gave this one to other people.

"Let's see, let's do the maloca now," said the four masters. So, there they did the maloca with a long pillar.

"We did the maloca." they said.

"How did you do it?", said the Uncle.

"We erected pillars like this, a long pillar in the middle and twelve short pillars around it."

"Ah! It is taking the design of a maloca a little bit further, that has already been paid, that is reserved for the yukuna, but for young men who are preparing to be maloca-makers. You are about to do a real maloca. For this one you can use parecú palm leaves."

So, they made a bigger maloca from the previous design.

"Well, let's go to the Uncle to see what he tells us this time," said the masters.

"Ah, that is a maloca! that is a maloca! What you did is not the management of anything, it is the management of the created jungle. It is part of the culture; it is the way of managing the world." 
"That is why we also come to ask you for palm leaves", said the masters. The Uncle already had leaves of carana ready; he had it in a box.

"You are already trained; you already have experience. So, I am going to grant you, I am going to pact with you on that knowledge. I am going to give you permission to make malocas."

Not even the four old wise men themselves could make malocas. That is why you cannot get to make a maloca in a rush, no! You have to pass through all that process that the masters did. They knew from the start that they were going to do a proper maloca but, to do that, they had to practice. So, to begin with, it was the little maloquita, then becoming bigger and bigger, as their knowledge grew. If you do a maloca without permission and training, you are going to end up fighting with people, you will do a maloca that is going to be bad, you will be cursed.

So, for us there is no maloca without permission. If you are going to do maloca, who gave you the permission to do it? You cannot say "I am a doctor" without graduating from university. The same is our culture. Being a maloquero [someone skilled to make malocas] is because you were granted that role. So, the Uncle said:

"I will give you the leaves in this little box. Each leaf is measured according to the length of the maloca. Here there are leaves for malocas of 5 palms, 6 palms, they are all there. Do not open the box."

And then the minor asked "Are all those palms in that box?"

"Yes. He said that, he said it will be enough, calculated, we must not be suspicious."

"No, I don't think so, because the structure of maloca is big. That little box? It is not enough." He insisted, "I'm going to look at a little, I'm not going to open."

That's where disobedience and mistrust come for us. Then he opened it a little and all came out. He reached to cover it, but the leaves already came out and left like a jet of gas. And so came the leaves that cover the entire jungle.

Then they scolded him and the minor said "I grabbed a little. It could serve for the new generations."

"Now we have to climb to the top of the maloca." Up there they opened the box, and the leaves were not enough for the entire roof.

"look, it was not enough, why did you open the box? what are we going to do?" They scolded again.

"Why are you scolding me? We are children of the living. What will the new generation do later? It is good that our brothers of the new generations have to pick part of the leaves from the jungle.

"And how are we going to knit?" Then they looked at the box for guidance, "Okay, so it will be", that is, it was not difficult for them to do that and they finished the maloca.

That is why for us the primordial leaves are the most important part of the maloca's roof and they are used for the top. These leaves never break while the lower part of the roof always has to be repaired.

And so was all maloca creation. For us, all things have an origin. Why does that exist? What principle? What function? How do they contribute to the balance of nature? Everything serves in nature, everything contributes. 


\section{Appendix B}

Tikuna artefacts

Interviewer: $\quad$ First author (JM)

Interviewee: $\quad$ A member of Tikuna people, teacher, collector of tikuna artefacts (TT)

Date:

Place:

March 2, 2020 - 10:28

File names:

Mocagua reservation and Leticia city

Files location:

200302_aa_tikuna_artefacts_rec_int-jmc

200302_aa_blowgun_rec_int-jmc

Language:

Fieldwork/data-collection/audio

Translation:

\section{Spanish / Tikuna}

First author

TT: This one here represents the master of a tree that is known in Spanish as "camphor", and this represents the master, that is, each mask represents some deity.

JM: Is this part of the mask?

TT: Yes, the mask is a whole. If you acquire those things separately, it does not have any meaning. It has to have all the pieces or the mask is incomplete.

JM: How did you get them?

TT: from the ritual of the pelazón (...) as I am setting up a museum about this

$\mathrm{JM}$ : Is that your project?

TT: It is my life project, it is not an academic matter... for example, this one here represents the snake [displaying the shields]

JM: Is the project part of your thesis?

TT: No. I'm a linguist I'm working on language acquisition, how kids learn my Tikuna language

JM: is it called tikuna?

TT: Well, it is called Magüta, badly called tikuna. I did my fieldwork with the only Tikuna group who decided to isolate themselves and not allow nobody to enter. To get there you have to do a lot of things and they do accept you; if they don't accept it, you can't go.

JM: (...) I am focused on artefacts just like you, understanding how these things were designed (...) for example, how did they design that?

TT: From the origin, the masters are absolutely right...the colours...and this also has an origin as a legacy, where did it come from? From mythology.

JM: Do you want to preserve this heritage in the museum?

TT: I called it a "museum", but it really is a learning centre. Objects mean many things: the origins, moral advice, songs and stories behind the object. The importance is in the living knowledge. There is little research on these things (...) At night they narrate how the origin of things was.

JM: Does the myth serve you so that everyone understands?

TT: It is a way of explaining things, a language that tells us that behind the artefact itself there are many things, norms, laws, physics, mathematics, geometry...

JM: and... how many artefacts have you collected?

TT: two thousand pieces badly counted (...) this is the blowgun

JM: how do you say blowgun in tikuna?

TT: 'ie... and this is what is put in the end to hunt [the poison]

JM: where do they get it from?

TT: from a tree...this one (pointing to a shield), as the grandparents explained to me, when there is a ritual, they carry it to dance

JM: because the tikuna were warriors?

TT: yes, they almost beat us, but when we were at war, we used these shields that were made of tapir skin that resist arrows and spears. 
JM: I want to do an in-depth study, not only from history, but as the Elder said, from a technical point of view. For example, if there are drawings or not, as in Western design, the designer makes sketches, here I have seen that you don't...

TT: Here, there are no previous drawings, but there is a prior idea. For this [pointing to the mask] it has to be said "I have this ritual and I need you to tell me how I should represent these deities." Therefore, you already know what to draw beforehand, there is already communication that comes from cultural learning for a long time ago (...) So, you don't make the mask as you wish. The master of nature, the master of time, the masters are warning you, they are making you see what is to be represented.

(...) if we see [the shields], there is the tucano ... the tiger. Some with feathers and others without feathers. For us Magüta, marriage alliances are by clans. There can be no marriage alliances between the same clan because an incest is being committed. Macaw with tiger if possible, or tucano with tiger. So those who know how to read these messages understand, they are texts. It is not a simple thing, there is a message there. It is not the object that matters, after the ritual, it is discarded (...)

JM: And to the ritual of "the pelazón" [in Spanish], how do you say it in tikuna?

TT: iu'

\author{
Appendix C \\ Manguaré, drums with hyper-communicative skills \\ Interviewer: $\quad$ First author (JM) \\ Interviewee: $\quad$ A member of Huitoto people, guide of an ethnographic museum (HG) \\ Date: \\ March 2, 2020 - 15:06 \\ Place: Leticia city \\ File names: $\quad$ 200302_aa_museum_1_rec_dc-jmc \\ Files location: $\quad$ Fieldwork/data-collection/audio \\ Language: Spanish / Huitoto \\ Translation: $\quad$ First author
}

JM: please introduce yourself

HG: my name is ..., I am indigenous form the Huitoto ethnic group, Eimen + clan of La Chorrera. We call ourselves Murui-Muinai. All here [at the museum] is an interpretation made by the first anthropologists that is not in accordance with what our thinking is. Since this is thought by someone from outside, they try to understand our world. Part of what is written is fine, there are other things that are not. For example, our names are not huitoto, yukuna, or tikuna. Each of us has a proper name. We are called Murui-Muinai, the Tikuna are called Magüta in their language.

JM: That is very important (...)

HG: (...) we have a traditional house that they call maloca. In our case, the maloca is held in four pillars. The pillars are carved, as the one we see here, according to the clan: the sparrow hawk clan, the turtle clan. For example, I am from the heron clan (...) Our maloca has 8 sides, the Yucuna's maloca is round and the Tikuna's has a gable roof, they have a plank floor. Our floor is simply adobe. Well, inside the maloca we have this instrument called manguaré. The small drum we call korab-rk and this is the big one that we call Jua+-ra+ (...) Manguaré is very sacred to us. The drums can't be displayed like this anywhere; they must be inside the maloca. The ones here are replicas. For example, this instrument is already 
more complex to manufacturing. We have four traditional dances: the fruit dance, the guadua dance, the charapa [Podocnemis expansa] dance and the boa dance. We use the manguare only for rituals, for funerals, to call people who are at work and to locate people who are lost in the jungle. The big one is the woman and the little one is the man. The holes represent the genitalia of both sexes. That is why the person who plays this instrument must be chosen by the Elders. No one else can touch or lean on it. The Elder says: you are going to play the manguaré because you have the required skills. The rest go to something else. So, he's the only one who can play it.

$\mathrm{JM}$ : in the pelazón [tikuna ritual] would you play this?

HG: No, because manguaré is ours. The Tikuna have no manguaré. Behind the manguaré there is a very scientific study that suddenly interests you

JM: Yes, I'm interested

HG: because behind the manguaré there are many things. For example, here women sing, here men do not sing. Women take it out on the man saying everything they want to say. It is a ritual for the tree (...) Behind the manguare there is a series of advice, teachings, and practices. For example, the practice of elaboration, because manguaré has precise techniques.

JM: Do they burn the trunk inside?

HG: Yes, inside, it comes to life. There is a lot of knowledge behind, that could be a good topic.

JM: Do you have references if it has been studied?

HG: No. Everyone says Manguaré, but from there no more. In detail, nothing. When you talk to the Elders, you realize that there is a lot of knowledge.

NJ: but being so ritual, isn't it difficult to access that information?

HG: well, let's get to that topic later. 